\title{
The association between intraocular pressure and different combination of metabolic syndrome components
}

\author{
JunSeok Son ${ }^{1}$, HyunMin Koh ${ }^{2}$ and JunHyuk Son ${ }^{3^{*}}$
}

\begin{abstract}
Background: Although the association between metabolic syndrome and intraocular pressure is well known, the relationship between the intraocular pressure and different combination of the components of metabolic syndrome has not been actively researched yet. The study aimed to investigate the relationship between the intraocular pressure and metabolic syndrome components with their different combinations.

Methods: Thirty-one thousand two hundred seventy one healthy people aged 19-79 who attended a community hospital for a health check-up between January 2011 and December 2013 were enrolled in the study. Subjects with a history of intraocular disease, at least in one eye and those receiving medical treatment for glaucoma were excluded. Metabolic syndrome was diagnosed following the criteria defined in Circulation 2009.

Results: Subjects with combination of three metabolic syndrome components of triglycerides, abdominal obesity, and fasting glucose had the highest intraocular pressure. And subjects with the combination of four components of blood pressure, high-density lipoproteins, triglycerides, fasting glucose had a significantly higher intraocular pressure than ones with the combination of all five metabolic syndrome components.

Conclusions: The difference in the risk of high intraocular pressure according to the different combination of the metabolic syndrome components could be confirmed. If additional follow-up studies are conducted, the findings can be used as an indicator for predicting intraocular pressure increases in patients with metabolic syndrome.
\end{abstract}

Keywords: Blood glucose, Blood pressure, High-density lipoproteins, Intraocular pressure, Metabolic syndrome, Triglyceride

\section{Background}

Glaucoma is a progressive ophthalmic disease that has the characteristics of optic disc cupping and visual field defects [1]. A family history of glaucoma, high myopia, and high intraocular pressure (IOP) are known as risk factors of glaucoma [2]. Among the various known risk factors, IOP is considered the most important and controllable [3-5].

Although the underlying mechanism of increased IOP is still unclear, a recent study suggested that it might be associated with various health indices, such

\footnotetext{
* Correspondence: sonjh@ynu.ac.kr

${ }^{3}$ Department of Ophthalmology, Yeungnam University College of Medicine,

\#317-1 Daemyung-dong, Nam-gu, Daegu 705-717, South Korea

Full list of author information is available at the end of the article
}

as hypertension, diabetes, and obesity [6-8]. Reaven [9] indicated that poor health indices, such as abdominal obesity, diabetes, and hypertension, share a single common mechanism that contributes to insulin resistance and glucose intolerance and therefore gave it the name "X syndrome", which has now been changed to metabolic syndrome (MetS).

The diagnostic criteria for MetS were first announced in 1998 by the World Health Organization (WHO) [10]. Later, the National Cholesterol Education ProgramAdults Treatment Panel III of the United States proposed MetS criteria that were more clinically applicable than those announced by the WHO, and these criteria are widely used [11]. Since then, various organizations have proposed slightly different criteria in consideration 
of ease in diagnosis, and, recently, in 2009, the International Diabetes Federation; National Heart, Lung, and Blood Institute; American Heart Association; World Heart Federation; International Atherosclerosis Society; and International Association for the Study of Obesity reorganized the various criteria for MetS [12]. Although many studies have reported on the association between MetS and IOP, the relationship between MetS components and IOP is not well known. With each component of MetS not independent but correlated, the present study aimed to identify the correlation of IOP with the number and combination of MetS components.

\section{Methods}

\section{Study subjects}

Healthy examinees $(31,271)$ who were between the ages of 19 to 79 and who attended a health promotion center in Changwon region of South Korea, between January 2011 and December 2013 were initially considered as study subjects. Before testing, each participant was interviewed by a trained nurse about previous health problems and medical history, including ocular diseases. A written informed consent was obtained from all participants and participants with a history of intraocular disease or surgery (in at least in one eye), those receiving medical treatment for glaucoma, and those who did not agree to involvement in this study were excluded. Finally, 28,754 healthy examinees were included in the present study.

The study protocol complied with the guidelines of the Declaration of Helsinki and was approved by the Institutional Review Board of Samsung Changwon Hospital, Sungkyunwhan University School of Medicine (2014-SCMC-101-00).

\section{Study method}

\section{Questionnaire}

A structured questionnaire survey was conducted through one-on-one interviews on the subjects' medical history, including hypertension, diabetes, dyslipidemia, and ophthalmological history, by surveyors who had received annual standardized training on data collection.

\section{Anthropometric measurements}

Height was measured to the nearest $0.1 \mathrm{~cm}$ by having the subject face forward with their heels and back of their head touching the wall, while weight was measured to the nearest $0.1 \mathrm{~kg}$ with an automated scale (GL-150, G-Tech International Co., Ltd., Seoul, Korea) with the subject wearing only light clothing. Waist circumference was measured with the subject positioned in an upright standing position with their feet together, and a tape measure was wrapped around the narrowest parts of the waistline between the ribs and iliac crest. The measurement was taken at the final stage of the breathing cycle without pressing the skin.

\section{Clinical examination}

Blood pressure (BP) was measured twice with an automatic BP monitor (Jawon Medical Co., Ltd., Seoul, Korea) while the subject was in a sitting position after at least $10 \mathrm{~min}$ of being stabilized and the two measured BP values were averaged. If the two measured values showed a discrepancy $\geq 5 \mathrm{mmHg}$, one additional measurement was taken. The subjects were restricted from smoking or consuming caffeine for $30 \mathrm{~min}$ or more prior to the measurements. Blood samples were collected intravenously after $8 \mathrm{~h}$ or more of fasting, and a blood test was performed with an enzyme-linked immunosorbent assay to measure triglyceride (TG), high-density lipoprotein cholesterol (HDLC), and fasting glucose (Hitachi Modular DPP, Roche Diagnostics K.K., Tokyo, Japan).

\section{Ophthalmologic examination}

The IOP was measured when the subject was in a sitting position with noncontact tonometry (Topcon CT60, Topcon Corporation, Tokyo, Japan). The IOP measurements were taken from the central corneal area by an experienced nurse, and the mean value from three measurements was used. All ophthalmological examinations were performed between 8 and 11 am to minimize any effects of diurnal variation, and any IOP $\geq 22 \mathrm{mmHg}$ was defined as ocular hypertension.

\section{Diagnostic criteria of MetS}

A diagnosis of MetS required the presence of 3 of the 5 diagnostic criteria of MetS listed below [12]. The criteria for waist circumference was based on the criteria proposed by the Korean Society for the Study of Obesity in 2006, which defined abdominal obesity as a waist circumference of $90 \mathrm{~cm}$ or more for males and $85 \mathrm{~cm}$ or more for females [13].

(1) Abdominal obesity: Male waist circumference $\geq$ $90 \mathrm{~cm}$; Female waist circumference $\geq 85 \mathrm{~cm}$

(2) Serum TG: $\geq 150 \mathrm{mg} / \mathrm{dL}$ or those taking medication for its treatment

(3) HDLC: male $<40 \mathrm{mg} / \mathrm{dL}$, female $<50 \mathrm{mg} / \mathrm{dL}$, or those taking medication for its treatment

(4) BP: $\geq 130 / 85 \mathrm{mmHg}$ or those taking medication for its treatment

(5) Fasting glucose: $\geq 100 \mathrm{mg} / \mathrm{dL}$ or those taking medication for its treatment

\section{Statistical analysis}

In order to examine the general characteristics of the study subjects, an independent t-test was used to compare 
the mean values of age, waist circumference, systolic and diastolic BP, fasting glucose, lipid profiles, and IOP in the group with IOP $\geq 22 \mathrm{mmHg}$ and the group with IOP $<22 \mathrm{mmHg}$. For comparisons of gender, the presence of MetS, and components of MetS, a chi-square test was used for the analysis. For the analysis of the components of MetS in the group with IOP $\geq 22$ $\mathrm{mmHg}$ and the group with IOP $<22 \mathrm{mmHg}$, a logistic regression analysis was used to obtain the odds ratio and $95 \%$ confidence interval. All of the statistical analyses were performed with SPSS, ver. 18.0 (IBM Corporation, Armonk, NY, USA).

\section{Results}

\section{General characteristics of study subjects}

Among the 28,754 study subjects, there were 16,728 males and 12,026 females, with a mean age of 41.26 years. Three thousand five hundred two out of 28,754 exhibited MetS, which was equivalent to a $12.18 \%$ prevalence rate. With respect to gender, males showed a prevalence rate of $12.65 \%(n=2116)$, while females showed a prevalence rate of $11.53 \%(n=1386)$. And IOP $\geq 22 \mathrm{mmHg}$ was found in 991 subjects (3.45\%), with 799 males (4.78 \%) and 192 females (1.60 \%) accounting for the total. A statistically significant difference in both prevalence rate and IOP value were found between males and females $(P<0.001)$ (Fig. 1).

The prevalence of MetS in the group with $\mathrm{IOP} \geq$ $22 \mathrm{mmHg}$ and the group with IOP $<22 \mathrm{mmHg}$ was 24.7 and $11.7 \%$, respectively, which was a significant difference $(P<0.001$; Fig. 2$)$. Moreover, when each of the mean values for the MetS components was compared between the group with IOP $\geq 22 \mathrm{mmHg}$ and the group with IOP $<22 \mathrm{mmHg}$, all showed a statistically significant difference $(P<0.001$; Table 1$)$.

\section{Relationship between MetS and IOP}

The mean IOP of the right eye in the subjects with MetS showed higher value of $16.05 \mathrm{mmHg}$ than that of $14.85 \mathrm{mmHg}$ in the subjects without MetS, which indicated a statistically significant difference $(P<0.001)$, while the mean IOP value of the left eye was 16.12 and $14.87 \mathrm{mmHg}$, respectively.

Among the 3502 subjects with characteristics that corresponded to MetS, $73.04 \%(n=2558)$ had three components of MetS, $23.50 \%(n=823)$ had four components, and $3.46 \%(n=121)$ had five components. Moreover, for the cases diagnosed with MetS, the group with IOP $\geq 22 \mathrm{mmHg}$ had more components of MetS than the group with IOP $<22 \mathrm{mmHg}(P<0.001)$. Having more components of MetS increased the probability of having a higher IOP ( $P$ for linear trend $<0.001$, Table 2).

Multiple logistic regression analysis adjusted for age and sex, revealed that the presence of more components of MetS had a statistically significant higher risk of increased $\operatorname{IOP}(P<0.001$, Table 3$)$.

In the group with $\mathrm{IOP} \geq 22 \mathrm{mmHg}$ and three components of MetS, the probability of having high IOP was not significantly different compared to the group without MetS when the criteria for HDLC was included, and the combination of $\mathrm{BP}, \mathrm{TG}$, and fasting glucose criteria showed the highest odds ratio of $3.73 \quad(P<0.001$, Table 4).

In the group with IOP $\geq 22 \mathrm{mmHg}$ and four components of MetS, only the combination of BP, HDLC, abdominal obesity, and fasting glucose criteria showed an increased

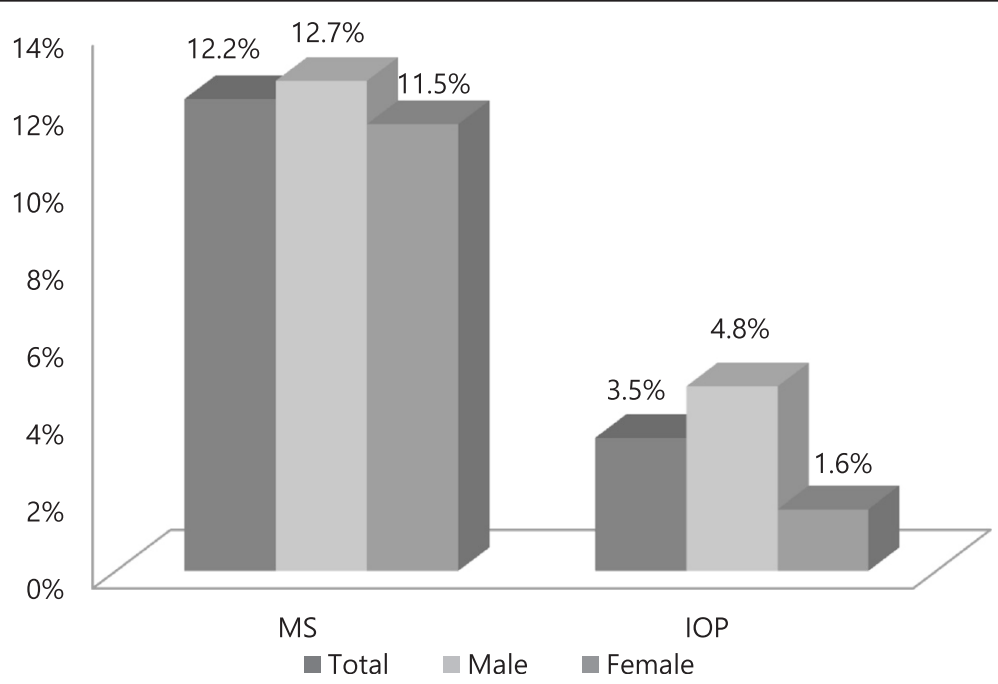

Fig. 1 Prevalence of metabolic syndrome and ocular hypertension according to gender. Abbreviations: MetS, Metabolic syndrome; IOP, Intraocular Pressure. $P<0.001$ Calculated by chi-square test 


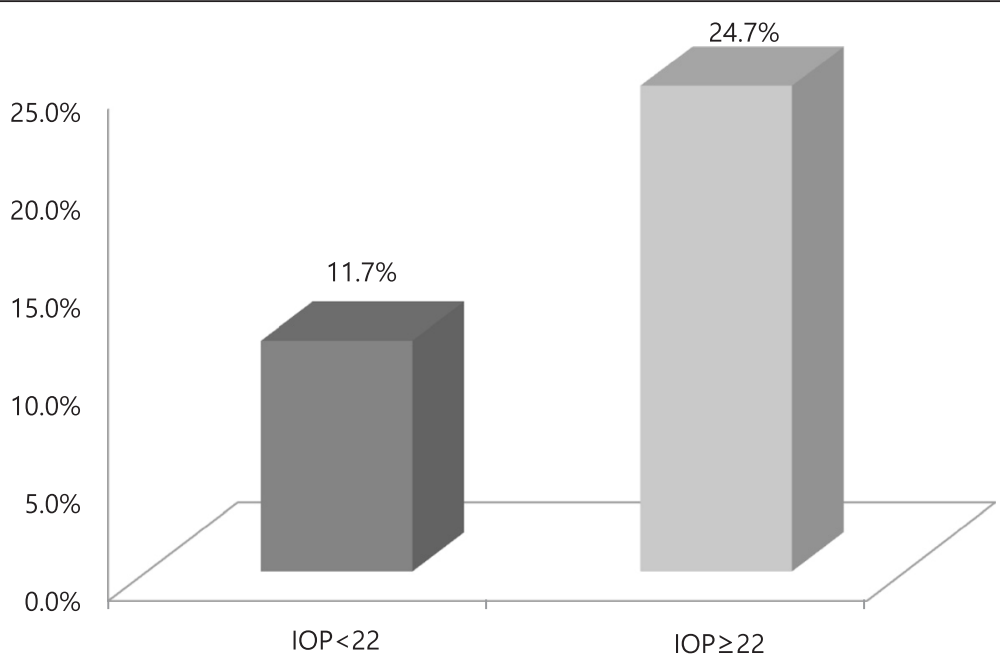

Fig. 2 Prevalence of metabolic syndrome according to ocular hypertension. Abbreviation: IOP, Intraocular Pressure. $P<0.001$ Calculated by chi-square test

IOP that was not statistically significant compared to the group without MetS $(P=0.550)$, while the combination of BP, HDLC, TG, and fasting glucose criteria showed the higher odds ratio of 9.39 than of the combination of all five components $(P<0.001$, Table 5).

\section{Discussion}

Metabolic syndrome is a type of disease cluster in which the primary risk factors for cardiovascular diseases, such as hyperglycemia, hypertension, dyslipidemia, and abdominal obesity, occur simultaneously, and many studies have examined this since the WHO presented the criteria for defining MetS in 1998 [10]. However, even before the concept of MetS was established, studies were conducted on the relationships between factors that comprise MetS and IOP. Many reports have indicated that, in people with obesity, which is one of the components of MetS, the IOP is increased because of a decrease in the aqueous humor outflow due to an increase in orbital fat and episcleral pressure [14-16]. Moreover, high BP increases the pressure in the intraocular ciliary artery, which promotes the formation of the aqueous humor that increases the IOP, and, hence, the association between IOP and hypertension has been confirmed in various studies $[16,17]$.

Higher serum TG, which is one of the two lipid parameters that comprise MetS, is known to increase the IOP. Klein et al. [18] indicated that, with higher serum TG levels, there is a greater amount of orbital adipose tissue, which causes an increase in orbital pressure, which causes an increase in IOP by inducing an increase in episcleral pressure and a decrease in aqueous humor outflow [19]. Moreover, it has been reported that higher fat intake and an increased severity of obesity results in increased TG levels, whereas HLDC,

Table 1 General characteristics of the study population

\begin{tabular}{lccc}
\hline & $1 \mathrm{OP}<22$ & $1 \mathrm{OP} \geq 22$ & $\mathrm{P}^{\mathrm{a}}$ \\
\hline Age (years) & $41.68 \pm 7.47$ & $40.83 \pm 7.20$ & $<0.001$ \\
Waist circumference $(\mathrm{cm})$ & $82.47 \pm 8.07$ & $86.23 \pm 8.45$ & $<0.001$ \\
Systolic blood pressure $(\mathrm{mmHg})$ & $122.72 \pm 16.22$ & $131.42 \pm 16.96$ & $<0.001$ \\
Diastolic blood pressure $(\mathrm{mmHg})$ & $73.18 \pm 11.40$ & $78.36 \pm 11.90$ & $<0.001$ \\
Fasting glucose $(\mathrm{mg} / \mathrm{dL})$ & $90.05 \pm 15.64$ & $96.78 \pm 24.35$ & $<0.001$ \\
Triglyceride $(\mathrm{mg} / \mathrm{dL})$ & $110.27 \pm 79.44$ & $146.29 \pm 105.67$ & $<0.001$ \\
HDL cholesterol $(\mathrm{mg} / \mathrm{dL})$ & $59.06 \pm 14.56$ & $55.52 \pm 13.61$ & $<0.001$ \\
Left IOP $(\mathrm{mmHg})$ & $14.72 \pm 2.44$ & $22.18 \pm 2.00$ & $<0.001$ \\
Right IOP $(\mathrm{mmHg})$ & $14.74 \pm 2.43$ & $22.15 \pm 2.12$ & $<0.001$ \\
\hline A & & & \\
\hline
\end{tabular}

Abbreviations: IOP intraocular pressure, HDL cholesterol high-density lipoprotein cholesterol Data are mean \pm standard deviation (SD)

${ }^{a}$ Calculated by independent t-test 
Table 2 Comparisons of intraocular pressures according to metabolic syndrome components

\begin{tabular}{lllll}
\hline MetS components & total & $\mathrm{IOP}<22$ & $1 \mathrm{OP} \geq 22$ & $\mathrm{P}^{\mathrm{a}}$ \\
\hline 3 & 2558 & 2397 & 161 & $<0.001$ \\
4 & 823 & 750 & 73 & $<0.001$ \\
5 & 121 & 110 & 11 & $<0.001$
\end{tabular}

Abbreviations: MetS metabolic syndrome, IOP intraocular pressure

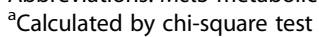

$P$ for linear trend $<0.001$

which is another component of MetS, has a low value, which is the result of increased episcleral pressure and IOP due to an increase in the vascular sclerosing changes and serum osmolality [16].

Hyperglycemia has also been reported to be closely associated with IOP. The continuous fluid inflow into the eyeball from osmotic pressure that is caused by hyperglycemia and the autonomic nervous system dysfunction that is observed in diabetics can induce increased IOP. Additional studies are needed to find out their exact mechanism [20-22].

In addition to the worldwide increase in the obese population, the prevalence of MetS is also showing an increasing trend, and it was reported that $15-25 \%$ of Korean adults suffer from MetS [23, 24]. For this reason, interest in MetS has risen, and many studies on the association between MetS and IOP have been published [25-29]. However, up to now, there have been no reports on the correlation with IOP based on the number and combination of MetS components.

The present study showed that, even within MetS group, the presence of more components of MetS was associated with a higher IOP. As explained earlier, this is because each MetS component is causing factor of increased IOP. In the group with three components of MetS, whitch included the criteria for TG, abdominal obesity, and fasting glucose, the highest risk for IOP increased was shown. In addition, the probability of the IOP increased was significantly higher in the groups that satisfied the criteria for BP, TG, and abdominal obesity; the combination of BP, TG, and fasting glucose criteria; and the combination of BP, abdominal obesity, and fasting glucose criteria.

Table 3 Association of intraocular pressures with metabolic syndrome components

\begin{tabular}{lllll}
\hline MetS components & ${\text { Crude } O R^{a}}^{a}$ & $P^{a}$ & Adjusted $\mathrm{OR}^{\mathrm{b}}$ & $\mathrm{P}^{\mathrm{b}}$ \\
\hline non MetS & 1.00 & & 1.00 & \\
3 & $2.21(1.85-2.63)$ & $<0.001$ & $2.16(1.81-2.58)$ & $<0.001$ \\
4 & $3.20(2.49-4.11)$ & $<0.001$ & $3.04(2.35-3.91)$ & $<0.001$ \\
5 & $3.29(1.76-6.13)$ & $<0.001$ & $3.48(1.85-6.53)$ & $<0.001$ \\
\hline
\end{tabular}

Abbreviations: MetS metabolic syndrome, OR odds ratio

${ }^{a}$ Calculated by simple logistic regression analysis

${ }^{\mathrm{b} C a l c u l a t e d}$ by multiple logistic regression analysis adjusted for age and sex
Table 4 Relationship between intraocular pressure and metabolic parameters in subjects with three components

\begin{tabular}{lllll}
\hline & $1 O P<22$ & $I O P \geq 22$ & crude $\mathrm{OR}^{\mathrm{a}}$ & $\mathrm{P}^{\mathrm{a}}$ \\
\hline non MetS & 24,506 & 746 & 1.00 & \\
$\mathrm{BP}+\mathrm{HDL}+\mathrm{TG}$ & 45 & 3 & $2.19(0.68-7.06)$ & 0.189 \\
$\mathrm{BP}+\mathrm{HDL}+\mathrm{WC}$ & 183 & 9 & $1.62(0.82-3.16)$ & 0.163 \\
$\mathrm{BP}+\mathrm{HDL}+\mathrm{DM}$ & 7 & 1 & $4.69(0.58-8.19)$ & 0.148 \\
$\mathrm{BP}+\mathrm{TG}+\mathrm{WC}$ & 485 & 35 & $2.37(1.67-3.37)$ & $<0.001$ \\
$\mathrm{BP}+\mathrm{TG}+\mathrm{DM}$ & 97 & 11 & $3.73(1.99-6.98)$ & $<0.001$ \\
$\mathrm{BP}+\mathrm{WC}+\mathrm{DM}$ & 441 & 35 & $2.61(1.83-3.71)$ & $<0.001$ \\
$\mathrm{HDL}+\mathrm{TG}+\mathrm{W}$ & 618 & 23 & $1.22(0.38-6.47)$ & 0.351 \\
$\mathrm{HDL}+\mathrm{TG}+\mathrm{DM}$ & 42 & 2 & $1.56(0.80-1.89)$ & 0.537 \\
$\mathrm{HDL}+\mathrm{WC}+\mathrm{DM}$ & 127 & 6 & $1.55(0.68--3.53)$ & 0.295 \\
$\mathrm{TG}+\mathrm{WC}+\mathrm{DM}$ & 352 & 36 & $3.36(2.37-4.77)$ & $<0.001$ \\
\hline
\end{tabular}

Abbreviations: IOP intraocular pressure, OR odds ratio, MetS metabolic syndrome, $B P$, blood pressure, $H D L$ high-density lipoprotein cholesterol, $T G$ triglyceride, WC waist circumference, $D M$ diabetes mellitus

Definitions of the metabolic syndrome components were as follows: Fasting glucose $\geq 100 \mathrm{mg} / \mathrm{dL}$ (includes diabetes); Blood pressure $\geq 130 / 85 \mathrm{mmHg}$ or being treated; Waist circumference, women $\geq 85 \mathrm{~cm}$, men $\geq 90 \mathrm{~cm}$;

Triglyceride $\geq 150 \mathrm{mg} / \mathrm{dL}$ or being treated; HDL cholesterol $<50 \mathrm{mg} / \mathrm{dL}$ or being treated

${ }^{\mathrm{a} C a l c u l a t e d}$ by simple logistic regression analysis

However, all of the cases that had the HDLC criteria as a component did not have a statistically significant higher risk of IOP. HDLC itself, as shown in Table 1, showed significant differences according to the IOP. However, in the combinations of MetS components, the effect on IOP was relatively limited and was actually influenced more by other factors. Such an interpretation can also be seen in other studies on IOP and lipid parameters, and many reports indicate that serum TG and total cholesterol are positively correlated with IOP, whereas HDLC does not show a corresponding

Table 5 Relationship between intraocular pressure and metabolic parameters in subjects with four or five components

\begin{tabular}{lllll}
\hline & $I O P<22$ & $I O P \geq 22$ & Crude $\mathrm{OR}^{a}$ & $P^{a}$ \\
\hline non MetS & 24,506 & 746 & 1.00 & \\
BP + HDL + TG + WC & 230 & 15 & $2.14(1.26-3.63)$ & 0.005 \\
BP + HDL + TG + DM & 28 & 8 & $9.39(4.26-20.66)$ & $<0.001$ \\
BP + HDL + WC + DM & 60 & 1 & $0.55(0.08-3.96)$ & 0.550 \\
BP + TG + WC + DM & 263 & 34 & $4.25(2.95-6.12)$ & $<0.001$ \\
HDL + TG + WC + DM & 169 & 15 & $2.92(1.71-4.97)$ & $<0.001$ \\
ALL(five components) & 110 & 11 & $3.29(1.76-6.13)$ & $<0.001$
\end{tabular}

Abbreviations: IOP intraocular pressure, OR odds ratio, MetS metabolic syndrome, $B P$ blood pressure, $H D L$ high-density lipoprotein cholesterol, TG triglyceride, WC waist circumference, DM diabetes mellitus

The definitions of the metabolic syndrome components were as follows: Fasting glucose $\geq 100 \mathrm{mg} / \mathrm{dL}$ (includes diabetes); Blood pressure $\geq 130$ / $85 \mathrm{mmHg}$ or being treated; Waist circumference, women $\geq 85 \mathrm{~cm}$, men $\geq$ $90 \mathrm{~cm}$; Triglyceride $\geq 150 \mathrm{mg} / \mathrm{dL}$ or being treated; $\mathrm{HDL}$ cholesterol $<50 \mathrm{mg} / \mathrm{dL}$ or being treated

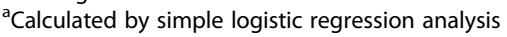


correlation with IOP. High HDLC is negatively correlated with IOP $[17,30,31]$, but one report claims a positive correlation with IOP as well [16]. A recent study on Koreans reported a negative correlation between HDLC and IOP in a multiple regression analysis that compensated for age, obesity, and BP [32]. But additional studies appear to be needed to understand the influence of HDLC on IOP in depth.

In groups with four or more components of MetS, the group with BP, HDLC, abdominal obesity, and fasting glucose criteria was the only group that did not show a significant correlation with IOP increase, and, interestingly, compared to the group with all five components, the group with BP, HDLC, TG, and fasting glucose criteria as its components showed the higher risk of IOP increase. However, whether the IOP increases in MetS groups are actually different based on their component combinations is something that requires additional study, as the number of subjects was too small compared to the entire study population when the groups were subdivided according to the MetS components. The genomic variates of subjects could be one of the factors which cause the IOP increases as well [33].

The present study had a few limitations. First, because the present study was based on the regular medical checkup in health promotion center, there was no information of cup to disc ratio and visual field analysis. So it was difficult to investigate the relationship between the glaucoma and metabolic syndrome components with their different combinations. Second, we did not measure central corneal thickness. However, if the IOP that was adjusted according to the central corneal thickness was used, it may have been possible to increase the accuracy. Third, although noncontact tonometers are reliable for testing within normal IOP ranges, the use of a Goldmann applanation tonometer would have given more accurate IOP measurements. Fourth, because the present study was a cross-sectional study, it was difficult to identify the causal relationships. Finally, there was no systemic approach about lifestyle that may have influenced IOP such as smoking history, drinking history, and the frequency of exercise.

Despite these limitations, this study has significance in that it showed not only the fact that each component of MetS is mutually dependent but also the fact that different combination of Mets components has correlation with IOP increase. If additional follow-up studies are conducted, the findings can be used as an indicator for predicting IOP increases in patients with MetS.

\section{Conclusions}

This study showed that there are the differences in the risk of high intraocular pressure according to the different combination of the metabolic syndrome components. In the group with three components of MetS, the combination of BP, TG, and fasting glucose criteria showed the highest risk of intraocular pressure elevation. In the group with four components of MetS, the combination of BP, HDLC, TG, and fasting glucose criteria showed the higher risk of intraocular pressure elevation.

\section{Abbreviations}

BP, blood pressure; DM, diabetes mellitus; HDLC, high-density lipoprotein cholesterol; IOP, intraocular pressure; MetS, metabolic syndrome;

TG, triglyceride; WC, waist circumference; WHO, World Health Organization

\section{Acknowledgements}

No funding was received by any of the authors in the writing of this manuscript.

Funding

No funding was obtained for this study.

Availability of data and materials

The data will not be shared because of personal data protection.

\section{Authors' contributions}

All authors participated in conception and design of the study. JSS and HMK collected the data. JSS and JHS were involved in analysis. JSS wrote the first draft of the maniscript, HMK and JHS revised the maniscript. All authors read and approved the final maniscript.

Competing interests

The authors declare that they have no competing interests.

Consent for publication

Not applicable.

Ethics approval and consent to participate

The study protocol complied with the guidelines of the Declaration of Helsinki and was approved by the Institutional Review Board of Samsung Changwon Hospital, Sungkyunwhan University School of Medicine (2014-SCMC-101-00).

\section{Author details}

${ }^{1}$ Department of Occupational and Environmental Medicine, Samsung Changwon Hospital, Sungkyunkwan University School of Medicine, Changwon, South Korea. ${ }^{2}$ Department of Family Medicine, Samsung Changwon Hospital, Sungkyunkwan University School of Medicine, Changwon, South Korea. ${ }^{3}$ Department of Ophthalmology, Yeungnam University College of Medicine, \#317-1 Daemyung-dong, Nam-gu, Daegu 705-717, South Korea.

Received: 17 September 2015 Accepted: 28 May 2016

Published online: 06 June 2016

References

1. Sommer A. Intraocular pressure and glaucoma. Am J Ophthalmol. 1989; 107(2):186-8.

2. Le A, Mukesh BN, McCarty CA, Taylor HR. Risk factors associated with the incidence of open-angle glaucoma: the visual impairment project. Invest Ophthalmol Vis Sci. 2003;44(9):3783-9.

3. Sommer A, Tielsch JM, Katz J, Quigley HA, Gottsch JD, Javitt J, et al. Relationship between intraocular pressure and primary open angle glaucoma among white and black Americans. The Baltimore Eye Survey. Arch Ophthalmol. 1991;109(8):1090-5.

4. Leske MC, Connell AM, Wu SY, Hyman LG, Schachat AP. Risk factors for open-angle glaucoma. The Barbados Eye Study. Arch Ophthalmol. 1995; 113(7):918-24

5. Goldberg I. Relationship between intraocular pressure and preservation of visual field in glaucoma. Surv Ophthalmol. 2003;48 Suppl 1:\$3-7.

6. Carel RS, Korczyn AD, Rock M, Goya I. Association between ocular pressure and certain health parameters. Ophthalmology. 1984;91(4):311-4. 
7. Schulzer M, Drance SM. Intraocular pressure, systemic blood pressure, and age: A correlational study. Br J Ophthalmol. 1987;71(4):245-9.

8. Kahn HA, Leibowitz HM, Ganley JP, Kini MM, Colton T, Nickerson RS, et al. The Framingham Eye Study. II. Association of ophthalmic pathology with single variables previously measured in the Framingham Heart Study. Am J Epidemiol. 1977:106(1):33-41.

9. Reaven GM. Role of insulin resistance in human disease. Diabetes. 1988; 37(12):1595-607

10. Alberti KG, Zimmet PZ. Definition, diagnosis and classification of diabetes mellitus and its complications. Part 1: diagnosis and classification of diabetes mellitus provisional report of a WHO consultation. Diabet Med. 1998;15(7):539-53.

11. Expert Panel on Detection, Evaluation, and Treatment of High blood Cholesterol in Adults. Executive summary of the third report of the National Cholesterol Education Program (NCEP) expert panel on detection, evaluation, and treatment of high blood cholesterol in adults (Adult Treatment Panel III). JAMA. 2001;285(19):2486-97.

12. Alberti KG, Eckel RH, Grundy SM, Zimmet PZ, Cleeman JI, Donato KA, et al. Harmonizing the metabolic syndrome: a joint interim statement of the International Diabetes Federation Task Force on Epidemiology and Prevention; National Heart, Lung, and Blood Institute; American Heart Association; World Heart Federation; International Atherosclerosis Society; and International Association for the Study of Obesity. Circulation. 2009; 120(16):1640-5. doi:10.1161/CIRCULATIONAHA.109.192644.

13. Lee SY, Park HS, Kim SM, Kwon HS, Kim DY, Kim DJ, et al. Cut-off points of waist circumference for defining abdominal obesity in the Korean population. Korean J Obes. 2006;15(1):1-9.

14. Shiose $Y$. The aging effect on intraocular pressure in an apparently normal population. Arch Ophthalmol. 1984;102(6):883-7.

15. Shiose $Y$, Kawase $Y$. A new approach to stratified normal intraocular pressure in a general population. Am J Ophthalmol. 1986;101(6):714-21.

16. Bulpitt CJ, Hodes C, Everitt MG. Intraocular pressure and systemic blood pressure in the elderly. Br J Ophthalmol. 1975;59(12):717-20.

17. Kim YH, Jung SW, Nam GE, Do Han K, Bok AR, Baek SJ, et al. High intraocular pressure is associated with cardiometabolic risk factors in South Korean men: Korean National Health and Nutrition Examination Survey, 2008-2010. Eye (Lond). 2014;28(6):672-9. doi:10.1038/eye.2014.43.

18. Klein $\mathrm{BE}$, Klein $\mathrm{R}$, Linton $\mathrm{KL}$. Intraocular pressure in an American community. The Beaver Dam Eye Study. Invest Ophthalmol Vis Sci. 1992;33(7):2224-8.

19. Han YS, Lee JW, Lee JS. Intraocular pressure and influencing systemic health parameters in a Korean population. Indian J Ophthalmol. 2014;62(3):305-10. doi:10.4103/0301-4738.116453.

20. Mitchell P, Smith W, Chey T, Healey PR. Open-angle glaucoma and diabetes. The Blue Mountains Eye Study, Australia. Ophthalmology. 1997;104(4):712-8.

21. Hennis A, Wu SY, Nemesure B, Leske MC. Hypertension, diabetes, and longitudinal changes in intraocular pressure. Ophthalmology. 2003;110(5):908-14

22. Mapstone R, Clark CV. Prevalence of diabetes in glaucoma. Br Med J. 1985; 291(6488):93-5.

23. Park HS, Kim SM, Lee JS, Lee J, Han JH, Yoon DK, et al. Prevalence and trends of metabolic syndrome in Korea: Korean National Health and Nutrition Survey 1998-2001. Diabetes Obes Metab. 2007:9(1):50-8.

24. Lee SY, Oh SW, Kim YJ, Cho BM, Hwang IK, Kim HH, et al. Predictive values of body mass index and waist circumference for cardiovascular risk factors in Korean: comparison with American population. Korean J Health Promot Dis Prev. 2005:5(2):97-113.

25. Park SS, Lee EH, Jargal G, Paek D, Cho SI. The distribution of intraocular pressure and its association with metabolic syndrome in a community. J Prev Med Public Health. 2010;43(2):125-30. doi:10.3961/jpmph.2010.43.2.125.

26. Imai K, Hamaguchi M, Mori K, Takeda N, Fukui M, Kato T, et al. Metabolic syndrome as a risk factor for high-ocular tension. Int J Obes (Lond). 2010; 34(7):1209-17. doi:10.1038/ijo.2010.32.

27. Lee $\mathrm{GH}$. The Association between metabolic syndrome and intraocular pressure. Korean J Health Promot. 2011;11(2):57-63.

28. Wygnanski-Jaffe T, Bieran I, Tekes-Manova D, Morad Y, Ashkenazi I, Mezer E. Metabolic syndrome: a risk factor for high intraocular pressure in the Israeli population. Int J Ophthalmol. 2015;8(2):403-6. doi:10.3980/j.issn.2222-3959. 2015.02.34.

29. Sahinoglu-Keskek N, Keskek SO, Cevher S, Kirim S, Kayiklik A, Ortoglu G, et al. Metabolic syndrome as a risk factor for elevated intraocular pressure. Pak J Med Sci. 2014:30(3):477-82. 10.12669/pjms.303.4514.
30. Chang YC, Lin JW, Wang LC, Chen HM, Hwang JJ, Chuang LM. Association of intraocular pressure with the metabolic syndrome and novel cardiometabolic risk factors. Eye (Lond). 2010;24(6):1037-43. doi:10.1038/eye.2009.247.

31. Kim MJ, Park KH, Kim CY, Jeoung JW, Kim SH. The distribution of intraocular pressure and associated systemic factors in a Korean population: The Korea National Health and Nutrition Examination Survey. Acta Ophthalmol. 2014; 92(7):e507-3. doi:10.1111/aos.12327.

32. Son JH, Chung YK, Son JS. Apolipoprotein B: Novel indicator of elevated intraocular pressure. Eye (Lond). 2015;29(10):1315-20. doi:10.1038/eye.2015.37.

33. Hysi PG, Cheng CY, Springelkamp H, Macgregor S, Bailey JN, Wojciechowski R, et al. Genome-wide analysis of multi-ancestry cohorts identifies new loci influencing intraocular pressure and susceptibility to glaucoma. Nat Genet. 2014;46(10):1126-30. doi:10.1038/ng.3087.

\section{Submit your next manuscript to BioMed Central and we will help you at every step:}

- We accept pre-submission inquiries

- Our selector tool helps you to find the most relevant journal

- We provide round the clock customer support

- Convenient online submission

- Thorough peer review

- Inclusion in PubMed and all major indexing services

- Maximum visibility for your research

Submit your manuscript at www.biomedcentral.com/submit
Biomed Central 